\title{
PROPERTIES OF FORESHOCKS AND AFTERSHOCKS IN THE AREA OF GREECE
}

\author{
Kourouzidis, M. C. ${ }^{1}$, Karakaisis, G. F. ${ }^{2}$, Papazachos, B. C. ${ }^{2}$, and Makropoulos, C. ${ }^{3}$ \\ ${ }^{1}$ Institute of Geodynamics, National Observatory of Athens, PO Box 20048, GR-11810 Athens, \\ Greece,m.kour@gein.noa.gr \\ ${ }^{2}$ Geophysical Laboratory, School of Geology, Aristotle University of Thessaloniki, PO Box 352-1, \\ 54124, Thessaloniki, karakais@geo.auth.gr, basil@lemnos.geo.auth.gr \\ ${ }^{3}$ Department of Geophysics and Geothermy, Faculty of Geology, National \& Kapodistrian \\ University of Athens, Univ. Campus, Ilisia, GR-15784, Athens, Greece, kmacrop@uoa.gr
}

\begin{abstract}
The results of the study of seismic sequences of all the mainshocks with $M \geq 5.6$ during 19111965 and $M \geq 5.0$ during 1966-1985 which occurred in the Aegean and surrounding area are presented. As regards the foreshocks, two relations have been proposed that can be used to determine (1) the probability that at least one foreshock, with magnitude $M_{f}$ or larger, will precede a strong $(M \geq 6.0)$ earthquake, and (2) the probability for the largest foreshock to occur during $t$ days before the mainshock. It was also found that the rate of foreshock occurrence, $N\left(T_{s}\right)$, increases as the time of the mainshock approaches and is described by a power-law function. The time and magnitude distribution of several foreshock sequences were also studied. The study of aftershock sequences concerned properties of their largest aftershock, the dependence of the duration and number of the aftershocks on the magnitude of the mainshock and the time and magnitude distribution of several aftershock sequences. The conclusion is that the study of a seismic excitation which is based on continuous monitoring and fast determination of the basic focal parameters of the earthquakes can contribute to clarify whether this activity evolves normally or not.
\end{abstract}

\section{INTRODUCTION}

The properties of the seismic sequences of strong mainshocks which occurred in the area of Greece have extensively been studied. Investigations on seismic sequences usually dealt with the magnitude and time distribution of foreshocks and aftershocks (Papazachos et al., 1967; Comninakis et al., 1968; Drakopoulos, 1968; Papazachos, 1973, 1974a, 1975; Karakaisis, 1984; Papadopoulos, 1988; Papanastasiou et al., 1989; Papazachos and Papazachou, 1989; Papadopoulos et al., 1991, 2000; Latoussakis et al., 1991; Drakatos and Latoussakis, 1994; Latoussakis and Drakatos, 1994, among others) as well as with the spatial distribution of foreshocks and aftershocks (Papazachos et al., 1982; Karakaisis et al., 1985; Papazachos et al., 2000). One of the most important results of the related work on the foreshocks is the observation that a large percentage of strong shallow mainshocks are preceded by foreshocks with their foci close to the focus of the mainshock, while the probability for an event to be a foreshock decreases with time. Moreover, the $b$ parameter of the magnitude distribution is smaller for the foreshocks than for the aftershocks or than the normal (background) seismic activity.

In the present work two catalogues of seismic sequences were used: (a) The catalogue of Comninakis and Papazachos (1989), which gives information on the basic focal parameters of the foreshocks and aftershocks of 417 shallow mainshocks that occurred in Greece and the surrounding regions with magnitudes $M \geq 5.6$ during 1911-1965 and $M \geq 5.0$ during 1966-1985. (b) The catalogue of Kourouzidis (2003) which contains the seismic sequences of 184 strong $(M \geq 5.0)$ shallow mainshocks that occurred"in this region during 1986-1997. For the compilation of the second catalogue, the earthquake catalogue of Papazachos et al. (2003) was used and the 
following declustering algorithm was applied: all shallow earthquakes with $M \geq 5.0$ were found and the largest of them was considered as the first mainshock. Then, all earthquakes which occurred within a space-time window, determined by proper relations between the mainshock magnitude, the corresponding fault length and the duration of the aftershock sequence (Papazachos \& Papazachou 1989, Papazachos 1989), were associated to this mainshock. The procedure is then repeated for the next mainshock (Kourouzidis 2003). The epicenters of the mainshocks of the 601 seismic sequences finally studied are shown in figure 1 (left).

\section{FORESHOCKS}

The epicenters of the strong $(M \geq 6.0)$ mainshocks which occurred in the studied area during 1911-1967 and were preceded by at least one foreshock with $M \geq 4.9$, during 1968-1997 with one foreshock with $M \geq 4.4$ and during 1990-1997 with one foreshock with $M \geq 4.0$ are shown in figure 1 (right). It can be observed that foreshocks precede mainshocks which occur along the Hellenic Arc and in particular in the lonian islands, as well as along the coast of Albania. It has to be noted however, that, since the accuracy for the estimation of epicenters is of the order of $20 \mathrm{~km}$, we cannot exclude the possibility that earthquakes which have been assumed to be foreshocks of certain mainshocks, they actually have occurred in adjacent faults. Hence, the association of these earthquakes to the respective mainshocks is based mainly on their temporal clustering.
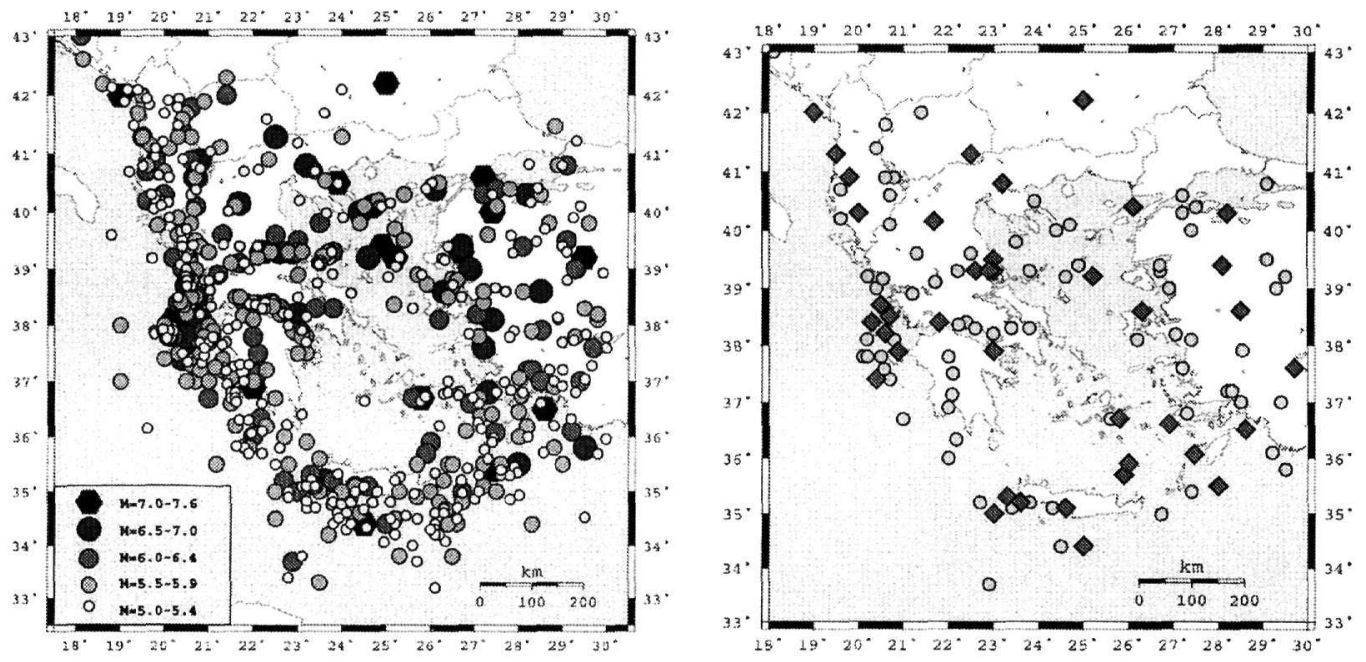

Figure 1. (left) The epicenters of all the shallow mainshocks of which the seismic sequences have been studied. (right) The epicenters of the strong $(M \geq 6.0)$ shallow mainshocks which occurred in the Aegean area during 1911: 1997. Diamonds denote epicenters of mainshocks with at least one foreshock with $M \geq 4.9$ during 1911-1967 or $\mathrm{M} \geq 4.4$ during 1968-1997 or with $\mathrm{M} \geq 4.0$ during 1990-1997 (Kourouzidis 2003).

From the examination of the cases of strong $(M \geq 6.0)$ mainshocks which occurred during 19111997 and were preceded by at least one foreshock with $M \geq 4.9$, during 1968-1997 by at least one foreshock with $M=4.4-4.8$ and during $1990-1997$ by at least one foreshock with $M=4.0-4.3$, it was found (fig. 2 left) that the probability, $P$, that at least one foreshock, with magnitude $M_{f}$ or larger, will precede a strong $(M \geq 6.0)$ earthquake, can be calculated by the relation:

$$
\log P=2.02-0.57 M_{f} \quad 4.0 \leq M_{f} \leq 5.4
$$

On the other hand, by using all foreshock sequences of mainshocks that occurred during 19111997 we found (fig. 2 right) that the probability, P, for the largest foreshock to occur during $t$ days before the mainshock, is given by the relation:

$$
P=0.79-0.41 \text { logt }
$$


Relations (1) and (2) are in agreement with the respective relations proposed by Papazachos \& Papazachou (1989).
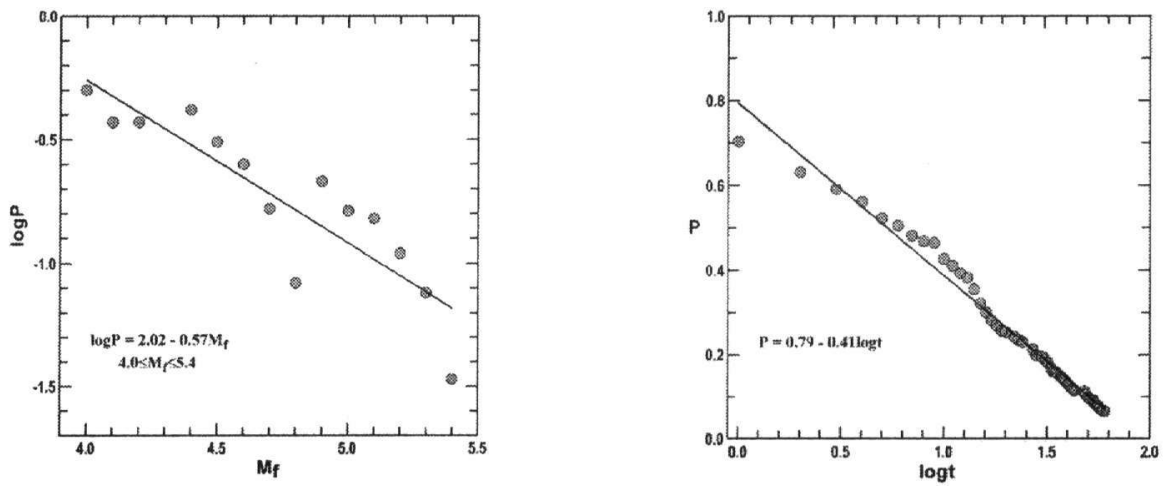

Figure 2. (left) Distribution of the probability, $P$, that at least one foreshock, with magnitude $M_{f}$ or larger, will precede a strong $(M \geq 6.0)$ earthquake in the Aegean area. (right) Distribution of the probability, $P$, for the largest foreshock to occur during $t$ days before the mainshock (Kourouzidis 2003).

In order to investigate variations of the foreshock occurrence rate and since no individual sequence contained enough events to define their temporal pattern of occurrence, all of the foreshock sequences were combined into a single sequence. This was done by putting all of the sequences onto the same axis, where the origin is the time of occurrence of each mainshock (fig. 3). It can be observed that the foreshock activity increases, as an average, about 40 days before the mainshock. Then, the foreshock occurrence rate becomes higher a few days before the mainshock and culminates a few hours before its generation. In all cases the occurrence rate, $n\left(T_{s}\right)$, follows a power-law of the form $n\left(T_{s}\right)=A\left(T_{s}\right)^{\text {-a }}$, as it has been suggested by Yamashita \& Knopoff (1989). In addition, it was found that the exponent $a$ is stable for all the time ranges examined (100, 10 and 1 day), in agreement with the foreshock occurrence model proposed by Yamashita \& Knopoff (1989).

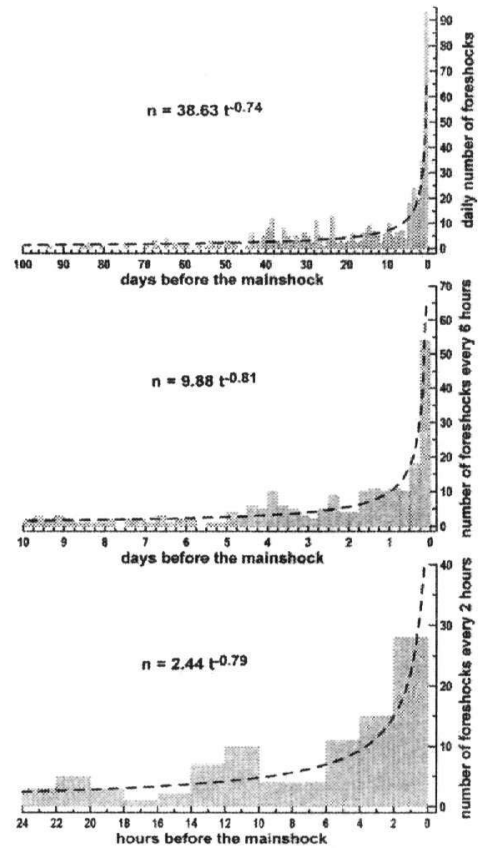

Figure 3. The time variation of the foreshock occurrence rate of all seismic sequences that occurred during 1911-1997. The rate of foreshock occurrence increases as the time of the mainshock approaches. This increase is independent of the time interval considered $(1,10,100$ days before the mainshock) (Kourouzidis 2003). 
The study of the time distribution of foreshocks is difficult since very few mainshocks are preceded by a significant number of foreshocks. For this reason, eight foreshock sequences which occurred during 1986-1997 and included at least 20 foreshocks each were studied, following the method suggested by Mogi (1962), Ranalli (1969) and Papazachos (1974a). It was found that the parameter $\mathrm{h}$ of the time distribution function is equal to $0.93 \pm 0.1$, whereas in some of them an indication of non-normal evolution of the seismic activity may be observed, but it is rather weak to be considered as a premonitory pattern of the oncoming mainshock.

The magnitude distribution of the foreshocks of the above mentioned sequences was also studied. It was found that the mean value of the parameter b of the Gutenberg \& Richter (1944) distribution function of those foreshock sequences, in which the magnitude range of the foreshocks was equal to or larger than 1.5, is equal to 0.67 , in agreement with previous results (Papazachos 1974b).

\section{AFTERSHOCKS}

Considerable work has been carried out in Greece concerning properties of the aftershock sequences. In a series of articles (Papazachos et al. 1967, Papazachos 1971, 1974b, Papazachos \& Papazachou 1989) it has been found that the mean value of difference between the magnitudes of the mainshock, $M_{0}$, and its largest aftershock, $M_{1}$, is equal to 1.1 and that this difference is independent of $M_{0}$. These authors (i.e. Papazachos et al. 1967, Papazachos 1971), also found that $M_{1}$ depends linearly on $M_{0}$. In a recent study Drakatos \& Latoussakis (2001) reported that the mean value of the difference $M_{0}-M_{1}$ is equal to 1.0 .

Kourouzidis (2003) used two data sets that consist of (a) aftershocks of all mainshocks which occurred in the studied area during 1911-1997 with $M_{0} \geq 6.0$ and (b) aftershocks of mainshocks which occurred during 1966-1997 with $5.0 \leq M_{0} \leq 5.9$, and found that the mean value of the difference $M_{0}-M_{1}$ is equal to 1.1 for the 108 cases with $M_{0} \geq 6.0$ and equal to 0.9 for the 293 cases with $5.0 \leq M_{0} \leq 5.9$. If all the cases are considered, then the average value of this difference is equal to 1.0 . The respective frequency histograms are shown in figure 4.
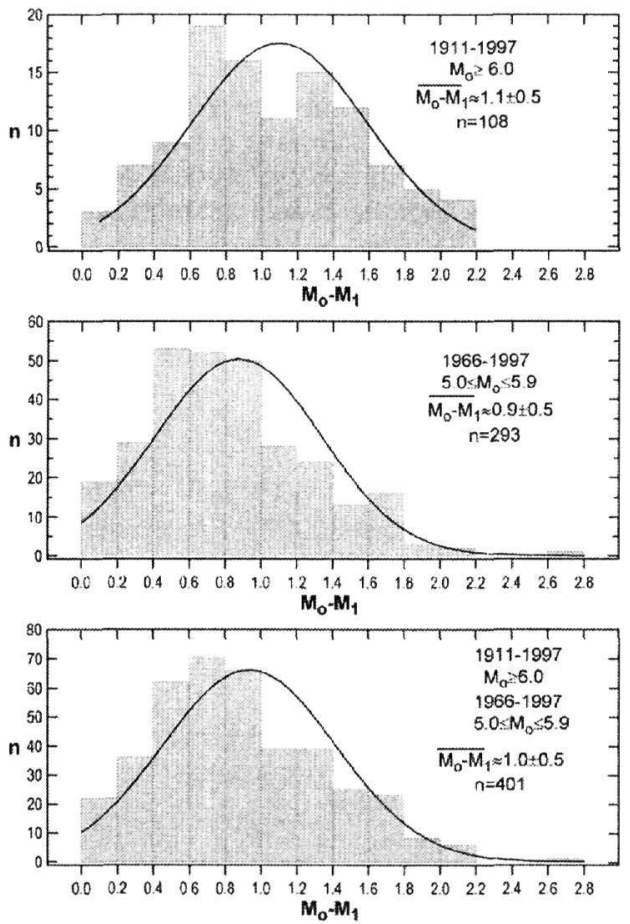

Figure 4. Frequency histograms of the difference of the magnitudes of the mainshock, $M_{0}$, and its largest aftershock, $M_{1}$, for two sets of seismic sequences. The mean value of this difference for both data sets $(n=401$ cases) is equal to $1.0 \pm 0.5$ (Kourouzidis 2003). 
Figure 5 (left) shows a plot of the difference $M_{0}-M_{1}$ against $M_{0}$, whereas the solid line corresponds to $M_{0}-M_{1}=1.0$. It can be observed that this difference does not depend on $M_{0}$. On the other hand, the dependence of $M_{1}$ on $M_{0}$ is quite obvious (fig. 5 , right) and can be expressed by the relation:

$$
M_{1}=-0.57+0.93 M_{0}
$$

The parameters of the relation (3) are almost equal to those found by Papazachos (1971) who used a data set of 216 aftershock sequences. A similar relation has been proposed by Drakatos and Latoussakis (2001).

The spatial distribution of $M_{0}-M_{1}$ was also examined but no dependence of this difference on the tectonic regime was found.
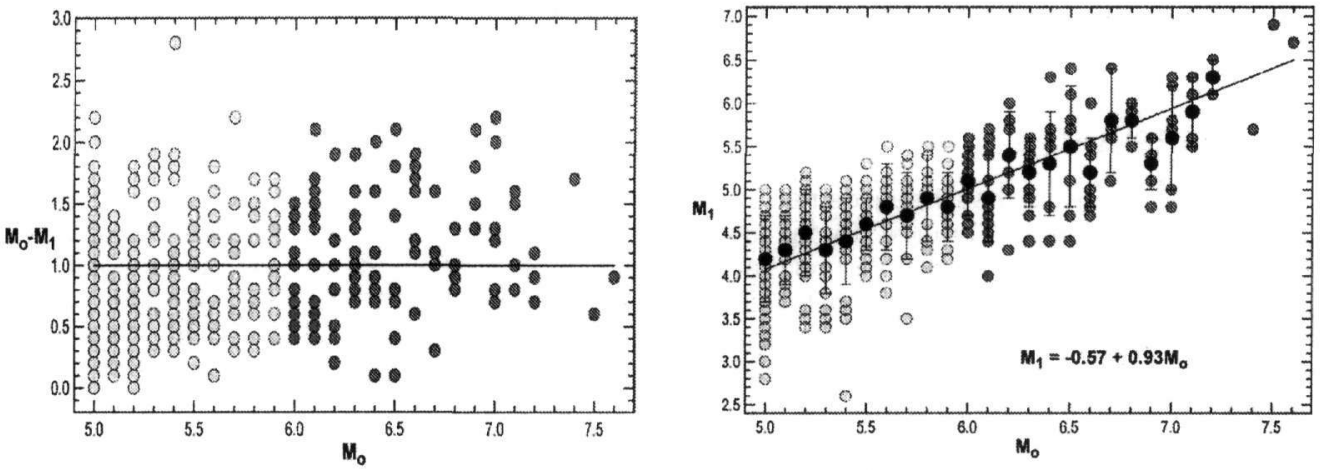

Figure 5. (left) Independence of the difference between the magnitude, $M_{0}$, of the mainshock and the magnitude, $M_{1}$, of its largest aftershock on $M_{0}$. Open and grey circles denote mainshock magnitudes with $5.0 \leq M_{0} \leq 5.9$ and $M_{0} \geq 6.0$, respectively, whereas the solid line corresponds to $M_{0}-M_{1}=1.0$. (right) Dependence of $M_{1}$ on $M_{0}$. Solid circles correspond to the average values of $M_{1}$ for each magnitude step of 0.1 for $M_{0}$ (Kourouzidis 2003).

Papazachos (1974b, 1975), studied the aftershock sequences of all strong ( $M \geq 6.0)$ mainshocks which occurred in the area of Greece during 1911-1973 and found that the cumulative frequency distribution, $N\left(T_{1}\right)$ of the time difference, $T_{1}$, between the mainshock and its largest aftershock follows a relation of the form $N\left(T_{1}\right)=c-k \log T_{1}$, where $c$ and $k$ are constants determined by the available data. Kourouzidis (2003) used all the available data and a similar relation, which can be used to calculate the probability, $P\left(T_{1}\right)$, that the largest aftershock will occur within $T_{1}$ days after the mainshock. This relation is:

$$
P\left(T_{1}\right)=0.61-0.31 \log T_{1}
$$

and shows that there is $39 \%$ probability for the largest aftershock to occur within the first day after the mainshock, $65 \%$ within the first week and $85 \%$ during the first month. Similar results have been found by Drakatos and Latoussakis (2001).

The dependence of the duration, $\mathrm{T}$, and the number, $\mathrm{N}$, of aftershocks of an seismic sequence on the mainshock magnitude, $M_{0}$, has also been examined, by the use of the aftershock sequences of all mainshocks with $M_{0} \geq 5.0$ that occurred during 1966-1997 in the Aegean and were followed by at least one aftershock with $M \geq 4.0$ (Kourouzidis 2003). The results, shown in figure 6 , indicate that both quantities are linearly related to the mainshock magnitude, $M_{0}$, according to the relations:

$$
\begin{aligned}
& \log N=-3.85+0.86 \mathrm{M}_{\circ} \\
& \log \mathrm{T}=-0.93+0.48 \mathrm{M}_{\circ}
\end{aligned}
$$

Similar results, based on smaller data sets, have been reported by Papazachos et al. (1967), Papazachos (1971), Papazachos \& Papazachou (1989) and by Drakatos \& Latoussakis (2001).

There are indications that the number of aftershocks depends not only on the magnitude of the mainshock but on the tectonics of the area of its occurrence. For example, Papazachos (1971) and Drakatos \& Latoussakis (2001) suggested that the aftershock activity may be an indication of heterogeneity of the crust in the vicinity of the mainshock rupture zone and that mainshocks which occur in the lonian islands are followed by more aftershocks than the mainshocks which occur in other areas of Greece. For this reason the logarithm of the number of aftershocks with $M \geq 4.0$ was calculated by the relation (5) for all the mainshocks with magnitude, $\mathrm{M}$, larger or equal to 5.0 and was subtracted from the logarithm of the aftershocks with $M \geq 4.0$ of the respective seismic 
sequences. The resulted differences were plotted on the mainshock epicenters (figure 7) and several zones with different levels of observed aftershock activity were defined in the Aegean area, in respect to the activity which is expected by the relation (5). It can be observed that intense aftershock activity follows mainshocks that occur at central lonian islands and the eastern Hellenic Arc. However, this activity may be attributed to triggering of the mainshocks in nearby faults.
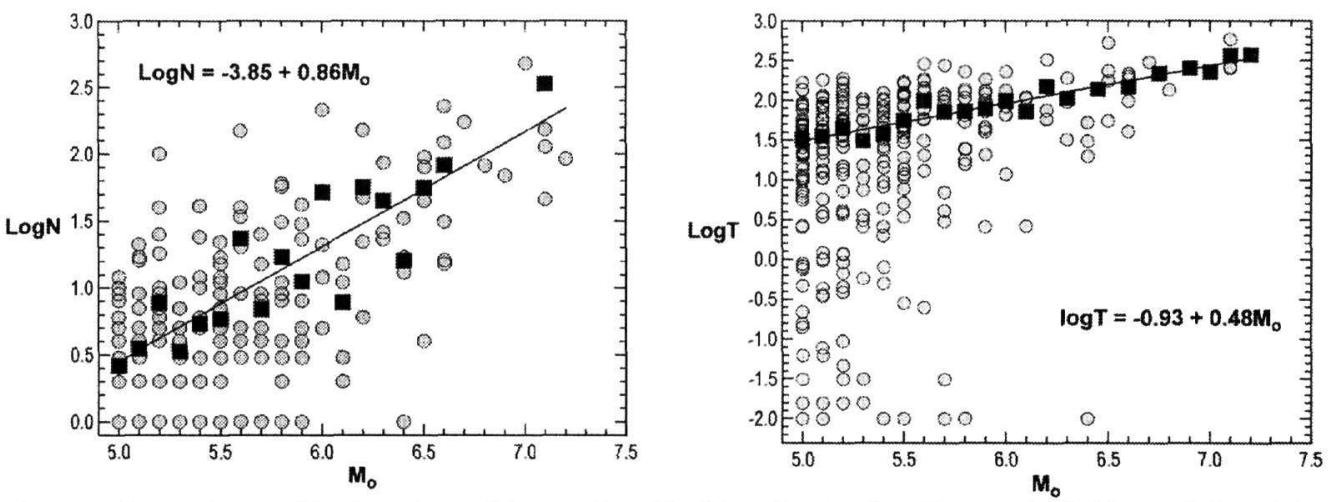

Figure 6. Dependence of the logarithm of the number, $N$, of the aftershocks with magnitude $M \geq 4.0$ (left) and the duration, ( $T$ in days) of an aftershock sequence on the magnitude, $M_{0}$, of the mainshock (right). Solid squares correspond to the average values of the quantities $\log N$ and $\log T$ for each magnitude step of 0.1 for $M_{0}$ (Kourouzidis 2003).

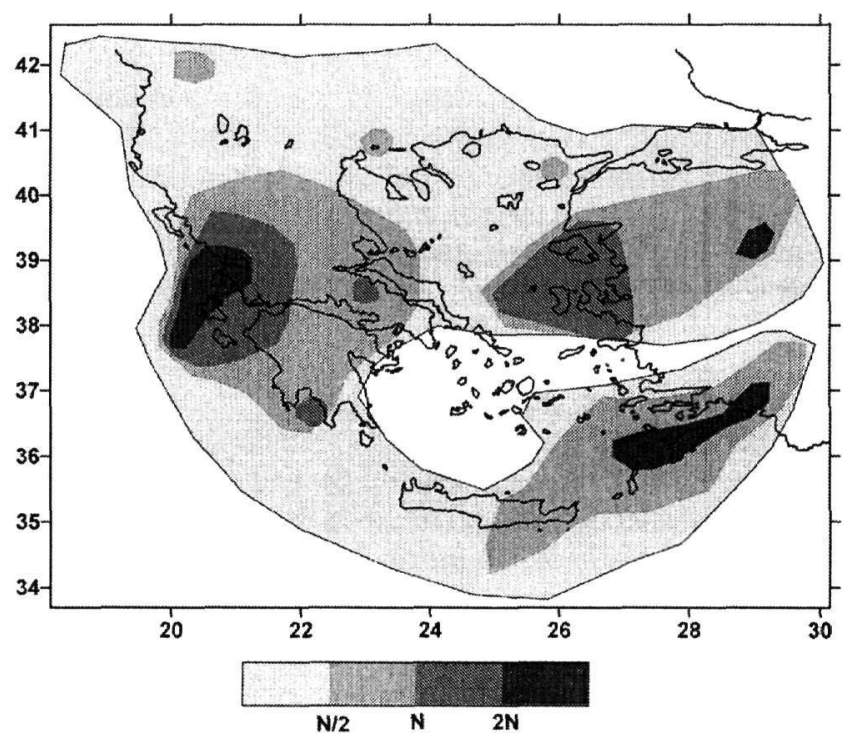

Figure 7. Geographical distribution of the aftershock activity in the Aegean area. The four zones correspond to aftershock activity smaller than the $50 \%$ of the normal activity, N/2, (expected by the relation 5 ), from $50 \%$ to normal activity, $\mathrm{N}$, from normal activity to two times the normal activity, $2 \mathrm{~N}$, and more than two times this activity (Kourouzidis 2003).

Previous research on the time distribution of the aftershocks that follow mainshocks in the Aegean area showed that the value of the parameter $p$ of the aftershock time distribution (Omori's law, 1894) is equal to 1.13 (Papazachos 1974c), whereas the $b$ value of the magnitude distribution (Gutenberg \& Richter 1944) has been found to be smaller for the foreshocks than for the aftershocks. An attempt was made to determine a representative value for the $p$ parameter by using a large data set. For this reason all the aftershock sequences (with at least 20 aftershocks each) of 
mainshocks that occurred in Greece during 1911-1997, and are included in both catalogues mentioned earlier, were considered and the time distribution of their aftershocks was determined. As it can be seen in figure 8 (left), the average value of the parameter $p$ is equal to $1.0( \pm 0.2)$ (Kourouzidis 2003). The magnitude distribution of the previously mentioned aftershock sequences has also been studied and the respective $b$ values have been calculated. However, it has been shown that reliable $b$ values can be calculated only when the magnitude range, $\Delta M$, of the events examined is at least 1.5 (Papazachos 1974d). Therefore, in the frequency histogram in figure 8 (right) only b values calculated for such aftershock sequences have been considered. It comes out that the mean b value for aftershocks is $1.0( \pm 0.2)$ (Kourouzidis 2003).
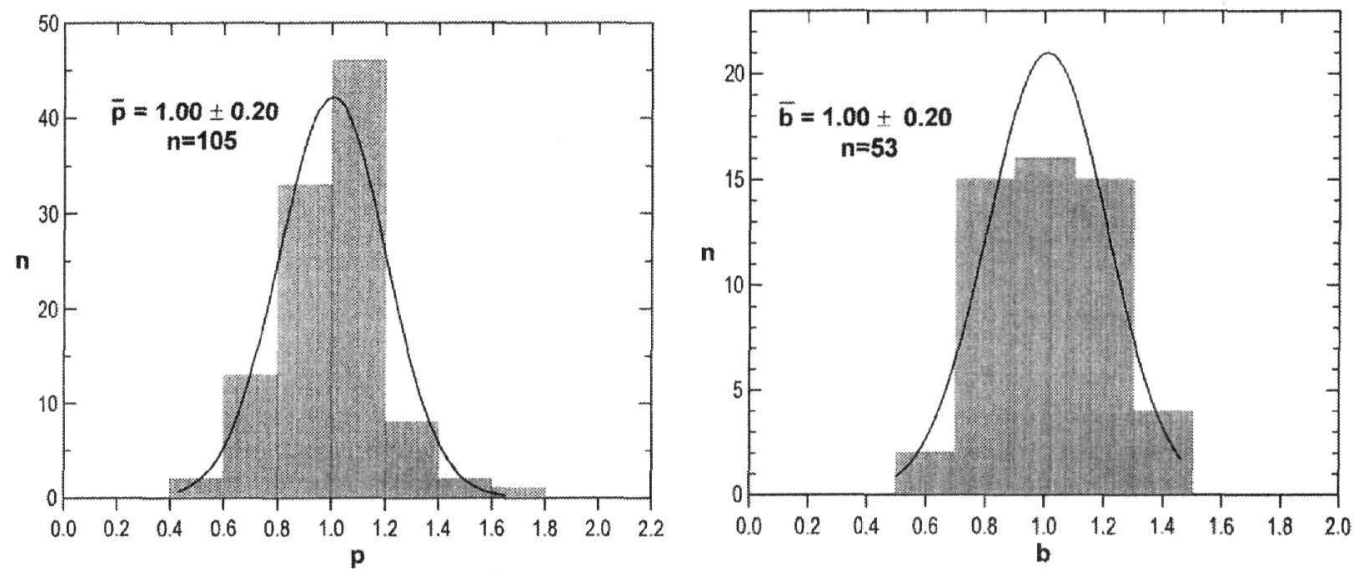

Figure 8. (left) Frequency histogram of the values of the $p$ parameter of the aftershock time distribution. 105 aftershock sequences that occurred during 1911-1997 were examined with at least 20 aftershocks each. (Right) Frequency histogram of the values of the $\mathbf{b}$ parameter of the magnitude distribution of the same aftershock sequences. The $\mathrm{b}$ values considered come from aftershock sequences in which the magnitude range of the aftershocks is at least 1.5 (Kourouzidis 2003).

The assessment of the evolution of the seismic activity in an area during a period of seismic excitation is a problem of significant social importance because it may lead to preparedness measures for the protection of the people. The first attempt to assess the evolution of an aftershock sequence has been made by Papazachos et al. (2000) and concerned the magnitude distribution of the aftershocks of the Athens 1999 ( $M=5.9)$ mainshock. The time variation of the mean magnitude,

$\bar{M}$, as well as the $b$ parameter was examined and it was concluded that this mainshock was followed by normal aftershock activity. On the other hand, the study of the time distribution of the foreshocks of the Mygdonia 1978 ( $M=6.5)$ mainshock, and the time variation of their mean magnitude, $\bar{M}$, revealed a non-normal evolution of the seismic activity (Papazachos et al. 1982, 1983). Lomnitz (1966) studied the aftershocks of the Kern County 1952 ( $M=7.5$, California) mainshock and observed that the mean magnitude, $\bar{M}$, of the aftershocks is constant. Utsu (1965) showed that the $b$ parameter varies inversely with $\bar{M}$, according to the formula:

$$
\overline{\mathrm{M}}=\frac{\log \mathrm{e}}{\mathrm{b}}+\mathrm{M}_{\min }
$$

where loge $=0.434$ and $\mathrm{M}_{\min }$ the minimum magnitude of the earthquakes considered.

The evolution of the aftershock activity of 16 strong mainshocks that occurred in the area of Greece during 1950-1997 and were followed by at least 150 aftershocks above a certain minimum magnitude, was studied, with the aim being to identify temporal variations of $\bar{M}$ that may indicate normal or non-normal evolution of the seismic activity (Kourouzidis 2003). In most of the examined cases the largest aftershock occurred within the first few hours to a few days after the respective mainshock and then the aftershock acitivity evolved normally, that is, there was no significant time variation of the mean magnitude (fig.9a). On the other hand, in some of the cases in which the largest aftershock occurred within several weeks to months after the mainshock, there was an increase of the mean magnitude (and consequently a decrease of the $b$ value) prior to its 
occurrence (fig. 9b). A M=4.6 earthquake occurred on April 4, 1995 in Chalkidiki (Northern Greece) which was followed one month later (May 5,1995 ) by a $M=5.8$ event (mainshock). Figure 9c shows
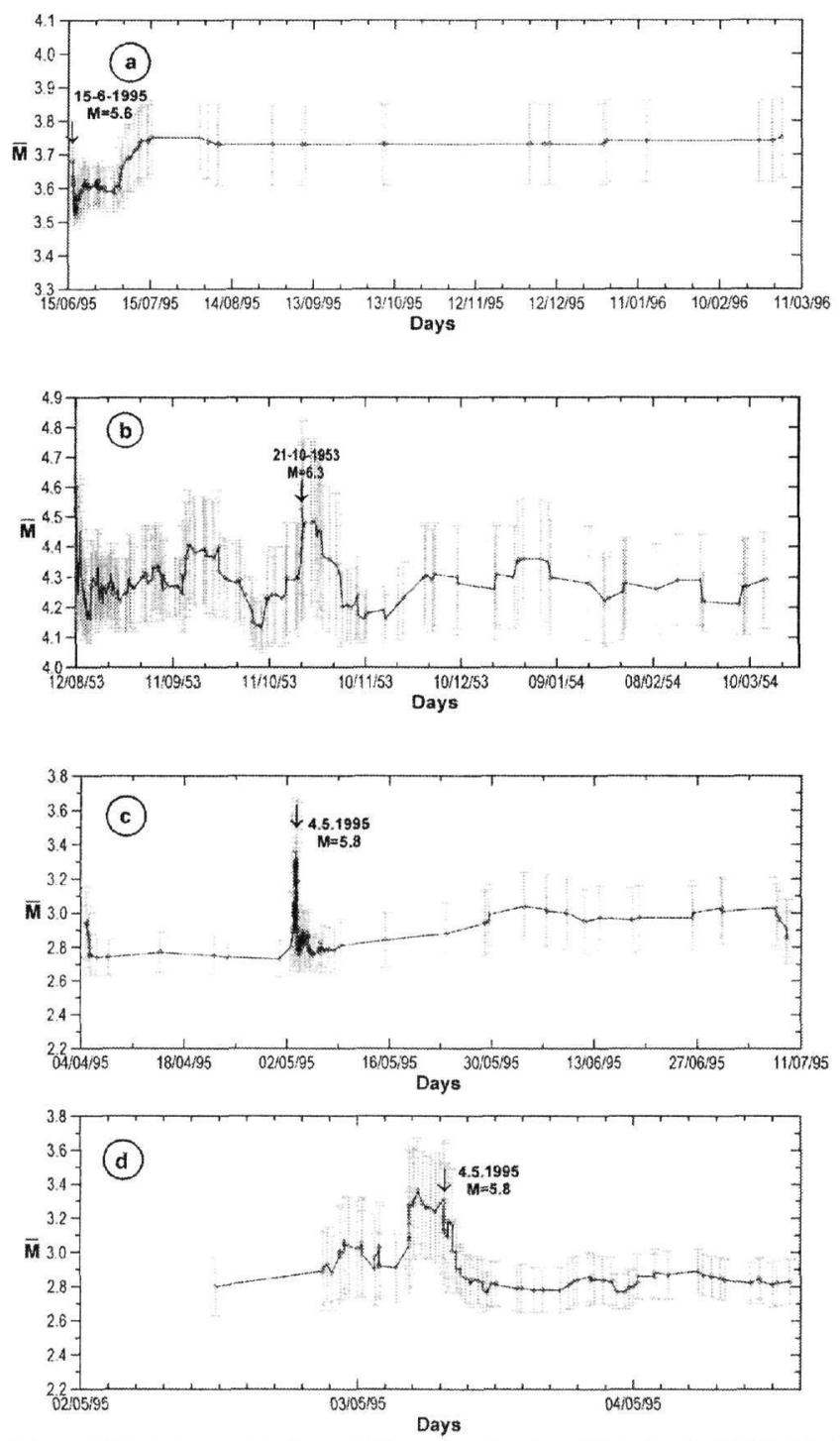

Figure 9. Time variation of the mean magnitude of the aftershocks of the Aegio $1995(M=6.4)$ and Cephalonia $1953(M=7.2)$ mainshocks ( $a$ and $b)$. Each point in these plots corresponds to the mean magnitude, $M$, of a number of aftershocks (i.e. 40 , with step one aftershock) which is plotted against the occurrence time of the last aftershock of the data sample. In each plot, the time axis starts on the mainshock origin time, while the origin time of its largest aftershock is denoted by the vertical arrow. Grey lines show the standard deviation of $\bar{M}$. In $\mathrm{C}$ and $\mathrm{d}$ the time variation of the mean magnitude before and after the Chalkidiki $1995 \quad(M=5.8)$ mainshock is shown (Kourouzidis 2003). $d$ is a magnification of $c$ and shows the time variation of the mean magnitude of the earthquakes which occurred 30 hours before and after the mainshock.

the time variation of the mean magnitude of all the earthquakes of the seismic sequence, while figure $9 \mathrm{~d}$ shows the time variation of the mean magnitude of the earthquakes which occurred 30 hours before and after the mainshock. From these two figures it comes out that the mean 
magnitude of the earthquakes after April 4 remained stable but increased about 10 hours before the mainshock on May 4.

\section{CONCLUSIONS}

The results of the study of the seismic sequences of strong mainshocks which occurred in Greece during 1911-1997 are presented. The data have been taken from the catalogues of Comninakis \& Papazachos (1989) and Kourouzidis (2003) for the periods 1911-1985 and 19861997, respectively. The data sample is obviously the largest ever used for similar studies in Greece.

The study of foreshocks resulted in the definition of two relations that can be used to determine the probability that at least one foreshock, with magnitude $M_{f}$ or larger, will precede a strong $(M \geq 6.0)$ mainshock (relation 1), as well as the probability for the largest foreshock to occur during $t$ days before the mainshock (relation 2). The time variation of the foreshock occurrence rate of all seismic sequences that occurred during 1911-1997 was also examined and it was found that the rate of foreshock occurrence increases as the time of the mainshock approaches and is described by a power law function of time, in agreement with previous results. This increase is independent of the time interval considered $(1,10,100$ days before the mainshock). From the 8 foreshock sequences that were studied (with more than 20 foreshocks each) it was found that the mean values of the parameters of the time and magnitude distributions were equal to 0.93 and 0.67 , respectively, in agreement to previous results.

As regards the aftershocks it was found that the mean value of the difference of the magnitude, $M_{1}$, of the largest aftershock from the magnitude, $M_{0}$, of the mainshock is equal to 1.0 (fig. 4). The magnitude difference $M_{0}-M_{1}$ is independent of the mainshock magnitude whereas the magnitude $M_{1}$ depends linearly on this magnitude (fig. 5). A relation which can be used to calculate the probability, $P\left(T_{1}\right)$, that the largest aftershock will occur within $T_{1}$ days after the mainshock, was also derived (relation 4). Two other relations were also derived between the number, $N$, of the aftershocks with $M \geq 4.0$ of all seismic sequences and the duration, $T$, of these sequences and the magnitude of the mainshock. The aftershock time distribution of seismic sequences with at least 20 aftershocks each was examined (105 cases) and it was found that the mean value of the parameter $p$ of the time distribution function is equal to 1.0, while from the study of the magnitude distribution of these sequences it was found that the mean value of the parameter b of the Gutenberg-Richter magnitude distribution function for the aftershock sequences in which the magnitude interval of their aftershocks was at least equal to 1.5 , is equal to 1.0 .

The results of the study of the time variation of the mean magnitude of the aftershocks that followed several strong mainshocks were also presented. It is concluded that the study of an aftershock sequence which is based on continuous monitoring and fast determination of the basic focal parameters of the aftershocks can contribute to clarify whether an aftershock activity evolves normally or not.

\section{AGKNOWLEDGEMENTS}

The maps were made by the use of the GMT software (Wessell and Smith, 1995). This work has been partially supported by the Greek Planning and Protection Organization (OASP), (Res. Comm. AUTH project 20242).

\section{REFERENCES}

Comninakis P., Drakopoulos J., Moumoulidis G. \& Papazachos B.C. 1968. Foreshock and aftershock sequences of the Cremasta earthquake and their relation to the waterloading of the Cremasta artificial lake. Annali di Geofisica, 21, 39-71.

Comninakis P.E., \& Papazachos B.C. 1989. Aftershocks and foreshocks sequences in Greece and surrounding area during the period 1911-1985. Publ. Lab. Geophysics, Univ. of Thessaloniki, 5, pp. 156.

Drakatos G \& Latoussakis J. 1994. Some features of aftershock patterns in Greece. Geophys. J. Int., 126, 123134.

Drakatos G., \& Latoussakis J., 2001. A catalogue of aftershock sequences in Greece (1971-1997): Their spatial and temporal characteristics. J. Seismology, 5, 137-145.

Drakopoulos J.K. 1968. Characteristic parameters of fore- and aftershock seismic sequences in the area of Greece. Ph. D. Thesis, Univ. of Athens, 128 pp. 
Gutenberg B. \& Richter C.F. 1944. Frequency of earthquakes in California. Bull. Seism. Soc. Am., 34, $185-188$.

Karakaisis G. 1984. Contribution to the study of the seismic sequences in the Aegean and surrounding area. Ph. D. Thesis, Univ. of Thessaloniki, pp. 192.

Karakaisis G.F., Karacostas B.G., Papadimitriou E.E., Scordilis E.M. \& Papazachos B.C. 1985. Seimic sequences in Greece interpreted in terms of barrier model. Nature, 315, 212-214.

Kourouzidis M.C. 2003. Study of seismic sequences in Greece and its contribution to earthquake prediction. Ph. D. Thesis, Univ. of Thessaloniki, pp. 150 (in Greek with English abstract).

Latoussakis J., Stavrakakis G., Drakopoulos J., Papanastassiou D. \& Drakatos G. 1991. Temporal characteristics of some earthquake sequences in Greece. Tectonophysics, 193, 299-310.

Latoussakis J. \& Drakatos G. 1994. A quantitative study of some aftershock sequences in Greece. Tectonophysics, 143, 603-616.

Lomnitz C. 1966. Magnitude stability in earthquake sequences. Bull. Seism. Soc. Am., 56, 247-249.

Mogi K. 1962. Study of elastic shocks caused by the fracture of heterogeneous materials and their relation to earthquake phenomena. Bull. Earthq. Res. Inst., Univ. Tokyo, 40, 125-73.

Omori F. 1894. On aftershocks of earthquakes. J. Coll. Sc. Imp. Univ. Tokyo, 7, 111-200.

Papadopoulos G.A. 1988. Long term accelarating foreshock activity may indicate the occurrence time of a strong shock in the western Hellenic arc. Tectonophysics, 152, 179-192.

Papadopoulos G.A., Makropoulos K.C. \& Dedousis V. 1991. Precursory variation of the foreshock fractal dimension in time. Int. Conf. on Earthq. Pred. Res., State-of-the-Art, Strasbourg, 15-18 Oct. 1991, 92-96.

Papadopoulos G.A., Drakatos G. \& Plessa A. 2000. Foreshock activity as a precursor of strong earthquakes in Corinthos gulf, central Greece. Phys. Chem. Earth, 25, 239-245.

Papanastassiou D. Drakopoulos J., Drakatos G, Latoussakis J. \& Stavrakakis G. 1989. v-value model for earthquake prediction. An application to some recent earthquake sequences in Greece. Bull. Geol. Soc. Greece, XXIII/3, 129-143.

Papazachos B.C. 1971. Aftershock activity and aftershock risk in the area of Greece. Ann. Geofis., 24, 439-456.

Papazachos B.C. 1973. The time distribution of the reservoir associated foreshocks and its importance to the prediction of the principal shock. Bull. Seism. Soc. Am., 63, 1973-1978.

Papazachos B.C. 1974a. On certain aftershock and foreshock parameters in the area of Greece. Ann. Geofis., $27,497-515$.

Papazachos B.C. 1974b. On the relation between certain artificial lakes and the associated seismic sequences. Eng. Geology, 8, 39-48.

Papazachos B.C. 1974c. On the time distribution of aftershocks and foreshocks in the area of Greece. Pure appl. Geophys., 112, 627-631.

Papazachos B.C. 1974d. Dependence of the seismic parameter $b$ on the magnitude range. Pure appl. Geophys., 112, 1059-1065.

Papazachos B.C. 1975. Foreshocks and earthquake prediction. Tectonophysics, 28, 213-226.

Papazachos B.C. 1989. Measures of the earthquake size in the area of Greece. $1^{\text {st }}$ Scientific Congress of the Hellenic Geophysical Union, Athens, April 1989, 437-447.

Papazachos B.C., Delibasis N., Liapis N., Moumoulidis G. \& Purcaru G. 1967. Aftershock sequences of some large earthquakes in the region of Greece. Ann. Geofis., 20, 1-93.

Papazachos B.C., Tsapanos T.M. \& Panagiotopoulos D.G. 1982. A preliminary pattern of earthquakes in northern Greece. Nature, 296(5854), 232-235.

Papazachos B.C., Tsapanos T.M. \& Panagiotopoulos D.G. 1983. The time, magnitude and space distributions of the 1978 Thessaloniki seismic sequence. In: The Thessaloniki, Northern Greece, earthquake of June 20, 1978 and its seismic sequence, Eds. B.C. Papazachos \& P.G. Carydis, Tech. Ch. Greece, Thessaloniki, $117-131$.

Papazachos B.C. \& Papazachou C. 1989. The earthquakes of Greece. Editions Ziti, Thessaloniki, 356 pp.

Papazachos B., Karakaisis G., Hatzidimitriou P., Karakostas B., Kiratzi A., Leventakis G., Margaris B., Panagiotopoulos D., Papadimitriou E., Papaioannou Ch., Papazachos C., Savvaidis A., Scordilis E., Theodulidis N., Tsapanos T. \& Dimitriou P.A. 2000. A procedure to assess the evolution of a seismic sequence. Ann. Geol. Pays Hell., XXXVIII, 119-128.

Papazachos B.C., Comninakis P.E., Karakaisis G.F, Karakostas B.G., Papaioannou Ch.A., Papazachos C.B. \& Scordilis E.M. 2003. A Catalogue of Earthquakes in Greece and Surrounding Area for the Period 550 B.C.2002. Publ. Geoph. Lab. Univ. of Thessaloniki.

Ranalli G. 1969. A statistical study of aftershock sequences. Ann. Geophys., 22, 359-397.

Utsu T. 1965. A method for determining the value of $b$ in a formula logn=a-bM showing the magnitudefrequency relation for earthquakes. Geoph. Bull. Hokkaido Univ., 13, 99-103.

Wessel P. \& Smith W. 1995. New version of the Generic Mapping Tools. EOS Trans. Am. Geophys. U., $76: 329$. Yamashita T. \& Knopoff L. 1989. A model of foreshock occurrence. Geophys. Jour., 96, 389-399. 